\title{
Carotid Artery Disease in Diabetic Patients: Contemporary Perspectives
} Nadeem Ahmed Siddiqui ${ }^{1 *}$, Asad Moosa ${ }^{1}$, Fareed Shaikh1, Waryam Saleh ${ }^{1}$ and Avgerinose Efthymios ${ }^{2}$

${ }^{1}$ Division of Vascular Surgery, Aga Khan University Hospital, Karachi, Pakistan

${ }^{2}$ Division of Vascular Surgery, University of Pittsburgh Medical Center, Pittsburgh, PA, USA

\begin{abstract}
Carotid artery disease is a significant contributor of diabetic patients' morbidity and mortality driven by its strong association with ischemic stroke. The link between carotid atherosclerosis and cerebrovascular or coronary artery disease is otherwise well established pointing to a high risk patient. This link gets particularly important in diabetic patients who demonstrate high rates of silent cardiovascular events, as a means of early detection of underlying atherosclerotic disease. Carotid ultrasonography now allows clinicians to visualize the characteristics of the carotid wall and lumen surfaces, to quantify the severity of local and systemic atherosclerosis and better guide the intensity of primary and secondary prevention strategies. Carotid revascularization remains the standard of care for high grade stenosis and while higher perioperative events and restenosis rates may be anticipated the benefits derived from the procedure still outweigh the risks. Current guidelines recommend carotid endarterectomy as a gold standard procedure; however carotid artery stenting can be a valid alternative in high medical risk symptomatic diabetic patients. Optimal glycemic control and confounding risk factor management can ameliorate short and longer term adverse events.
\end{abstract}

Keywords: Carotid artery disease; Carotid atherosclerosis; Carotid plaque; Carotid intima media thickness; Carotid endarterectomy; Carotid stenting; Carotid restenosis

\section{Introduction}

Cardiovascular diseases remain one of the main causes of morbidity and mortality in diabetic patients manifesting as silent and eventually clinically significant coronary, cerebrovascular and limb vascular events. While the association of diabetes with extracranial carotid atherosclerosis was a subject of debate in the recent past, further studies have now confirmed its positive independent role in the development of carotid disease and subsequent related events like transient ischemic attacks and ischemic stroke [1-4]. Alongside, carotid disease progression through ultrasonography is currently widely suggested as a means of screening global atherosclerotic changes in type 2 diabetes [5-7]. The current review summarizes the distinct characteristics of carotid atherosclerosis and contemporary management in diabetic patients.

\section{Epidemiology}

Patients with type 2 diabetes have thicker and stiffer carotid arteries and are more likely to suffer from cerebrovascular events [1$4,8,9]$. Carotid plaques are identified in approximately $30 \%$ of newly diagnosed type 2 diabetic patients and this percentage doubles within a 2 year follow up $[10,11]$. The respective rate can be as high as $50-70 \%$ in patients with known diabetes, however the severe forms of the disease (ICA stenosis $>60 \%$ ) are only seen in approximately $5 \%$ of the patients [10-12]. The atherosclerotic burden seems to be different between the left and right carotid artery, with the left being more susceptible to carotid atherosclerosis, potentially because the left carotid artery is a first order branch of the aorta receiving a higher hemodynamic stress [13-16].

Diabetes increases the risk of stroke by 1.8-6 folds [1]. Alongside, diabetes prevalence ranges between $21-69 \%$ among patients with acute ischemic stroke, a 3 fold higher rate when compared to matched controls $[2,3,17,18]$. These patients are being anticipated to a have higher incidence of post stroke mortality, dependency state and recurrent stroke compared to non-diabetics [19-23]. While there are no clear gender differences, ethnicity is associated with different stroke rates in diabetic patients [24-27]. Over the past years, the risk of stroke has declined significantly in black population as compared to a stable incidence in white population [26]. Similar results were also reported in the Baltimore-Washington Cooperative Young Stroke Study, which demonstrated that the presence of diabetes markedly increased the odds ratio for stroke from $3.3 \%$ in the black population to as high as $23.1 \%$ in the white population [27].

\section{Physiology of Carotid Atherosclerosis in Diabetes}

Understanding plaque morphology and vulnerability is critical for the prognosis of carotid disease. Atherosclerotic plaques prone to rupture, referred as vulnerable plaques, are characterized by a lipidrich necrotic core and a thin fibrous cap, result of a high inflammatory activity. This further relates to increased vascularization, loss of vascular smooth muscle cells (VSMCs) and degradation of structural components (e.g. collagen) by matrix metalloproteinases (MMPs) The mechanisms responsible for the increased cardiovascular risk in diabetes remain to be fully understood, but much attention has pointed to the role of inflammation, vascularization and impaired fibrous repair capacity within the plaque.

Carotid atherosclerosis is associated with chronic low-grade systemic inflammation as assessed by serum elevated C-reactive protein and fibrinogen [28]. These inflammatory biomarkers are even more elevated in diabetic patients [29]. Studies on coronaries have shown that plaques from subjects with type 2 diabetes have more inflammatory cells and a greater necrotic core [30,31]. It has also been demonstrated that carotid plaques from diabetic patients with

${ }^{*}$ Corresponding author: Siddiqui NA, Division of Vascular Surgery, Aga Khan University Hospital, Karachi, Pakistan, Tel: 0213-4864272; E-mail: nasiddiqui81@yahoo.com

Received March 12, 2019; Accepted March 20, 2019; Published March 25, 2019

Citation: Siddiqui NA, Moosa A, Shaikh F, Saleh W, Efthymios A (2019) Carotid Artery Disease in Diabetic Patients: Contemporary Perspectives. J Blood Lymph 9: 238.

Copyright: @ 2019 Siddiqui NA, et al. This is an open-access article distributed under the terms of the Creative Commons Attribution License, which permits unrestricted use, distribution, and reproduction in any medium, provided the original author and source are credited. 
symptomatic atherosclerotic disease have a higher density of vessels and increased VEGFR-2 expression in the plaque shoulder regions when compared to non-diabetics [32]

According to other studies diabetic plaques may be more prone to rupture not necessarily due to increased vascular inflammation but due to impaired repair responses [33]. Edsfeldt et al. demonstrated that inflammatory markers (macrophage inflammatory protein-1 $\beta$, IL-6, MMP-1, MMP-9, TIMP-1) are in fact not associated with diabetes; however carotid plaques from diabetic subjects have reduced content of fibrous connective tissue proteins required to maintain plaque stability (extra cellular matrix proteins,collagen and elastin) as well as lower levels of factors known to promote the formation of fibrous tissue such as PDGF (stimulates vascular smooth muscle cell proliferation and synthesis of extracellular matrix proteins) and MMP -2 (degrades collagen IV, a key regulatory step for conversion of VSMC into the synthetic, proliferative repair phenotype required for induction of intima repair response) [33]. This could make diabetic carotid plaques more prone to rupture, requiring a significantly lower level of inflammatory activation to cause symptoms. Esposito et al. confirmed through MRI imaging that diabetes is otherwise associated with higher risk lesions matching vulnerable carotid plaque characteristics [34].

\section{Carotid Intima Media Thickness in Diabetes}

The close association between carotid atherosclerosis and cerebrovascular or coronary artery disease is well established. Carotid ultrasonography has allowed clinicians to visualize the characteristics of the carotid wall and lumen surfaces to quantify the severity of atherosclerosis. This becomes particularly important in diabetic patients who show high rates of silent myocardial events [35]. Carotid intima-media thickness (CIMT) measured with B-mode ultrasound has been confirmed to be a quantitative and reproducible measure of atherosclerosis in other vascular beds and a predictor of cardiovascular events [36,37]. CIMT at baseline was a strong predictor of non-fatal coronary heart disease in a study of 287 Japanese diabetic patients followed up for 3 years [38]. More recently similar results were reproduced confirming that CIMT could be a predictor for the development of cardiovascular events in a study of 469 asymptomatic type 2 diabetic patients followed up for 6.1 years [39]. Other studies however have indicated that the presence of carotid plaques may be a more accurate surrogate marker of generalized atherosclerosis $[10,39]$. Irrespective, it is evident that carotid ultrasound in diabetic patients, to assess the CIMT and/or presence of carotid plaques, is a valuable tool to screen their atherosclerotic burden and guide appropriate medical treatment. CIMT measurement, however, has not been widely accepted as it still has several limitations (including establishing a reference range and comparisons between measurements carried out in different and even the same unit), thus further studies are awaited.

\section{Medical Management of Carotid Disease in Diabetes}

Optimal medical treatment for carotid artery disease is currently well established both for primary and secondary prevention, and includes atherosclerotic risk factor management, antiplatelets and lipid lowering therapies. Glycemic control in diabetic patients with carotid disease (or any other atherosclerotic disease) is a crucial strategy to prevent disease progression and/or symptomatic conversion, however intensive therapies targeting $\mathrm{HbAlc}<6 \%$ did not show reduction in stroke rates $[40,41]$. Therefore targeting $\mathrm{HbAlc}$ of $7 \%$ is currently recommended [42]. Insulin sensitizers seem to be superior over insulin secretagogues. In the 10-year follow up of United Kingdom Prospective Diabetes Study (UKPDS) the metformin treated arm had 33\% reduction in myocardial infarction and $27 \%$ reduction in all-cause mortality, both significantly more than that in the patients in the sulfonylurea $[43,44]$.

Blood pressure control seems to be more important than aggressive glycemic control in stroke risk reduction as demonstrated by the UKTIA Trial [45]. Randomized clinical trial evidence among high-risk diabetic patients indicates that there is no benefit in achieving an aggressive systolic blood pressure (SBP) of $<120$ versus $<140 \mathrm{~mm} \mathrm{Hg}$ [46]. Current recommendation is that hypertensive patients $(>140 / 90$ $\mathrm{mmHg}$ ), should start pharmacotherapy in addition to life style modification to achieve SBP $<140 \mathrm{mmHg}$ and diastolic blood pressure (DBP) $<90 \mathrm{mmHg}$. Lower targets ( $\mathrm{SBP}<130 \mathrm{mmHg}, \mathrm{DBP}<80 \mathrm{mmHg}$ ) can be appropriate in certain individuals, such as younger patients if they can be achieved without undue treatment burden [47]

Statins, given their anti-inflammatory pleiotropic effects, can be beneficial in diabetics even if cholesterol levels are not elevated $[48,49]$. Statin therapy is recommended for all patients with diabetes and it should be of high intensity for those with known cerebrovascular disease (LDL-C $<70 \mathrm{mg} / \mathrm{dL}$ ) [47].

Overall, intensive management of all cardiovascular risk factors can result in a net benefit of diabetic patients with carotid atherosclerosis As shown in a recent prospective study of patients with type 2 diabetes and at least two insufficiently treated cardiovascular risk factors (e.g. $\mathrm{HbA} 1 \mathrm{C}>7.5 \%$, LDL-C $>120 \mathrm{mg} / \mathrm{dl}$ or blood pressure $>140 / 90 \mathrm{mmHg}$ ), intensive treatement to reach targets of $\mathrm{HbAlc} \leq 6.5 \%, \mathrm{LDL}-\mathrm{C}<100$ $\mathrm{mg} / \mathrm{dl}$ and blood pressure $\leq 130 / 80 \mathrm{mmHg}$ resulted in a significant regression in mean CIMT at 2 years [50].

\section{Carotid Revascularization in Diabetes}

Carotid endarterectomy (CEA) is considered the gold standard in symptomatic patients with $>50 \%$ internal carotid artery stenosis and is recommended in asymptomatic internal carotid artery stenosis $>70 \%$ provided that perioperative risk of stroke and death is less than $3 \%$ and the patient has an estimated survival of at least 5 years [49,51]. Carotid artery stenting (CAS) has been associated with higher perioperative risk of stroke and is currently recommended as an alternative for symptomatic patients at high medical or anatomic risk [49,51]. Several studies have demonstrated a mild to moderate effect of diabetes on the 30-day risk of stroke and death after carotid revascularization, as well as a long term effect on mortality and restenosis; some suggesting that it may not be diabetes itself but the co-existing cardiovascular risk profile.

In one of the largest CEA series (>13,000 CEAs, VA database (NSQIP)), the presence of insulin-dependent diabetes was the strongest independent patient risk factor for an adverse outcome on the basis of an increased risk of cardiac events and death [52]. In another large series assessing the outcomes of 4,305 carotid endarterectomies ( 883 diabetics vs. 3422 non diabetics) diabetics had a higher 30-day mortality (OR 3.5, $\mathrm{P}=0.002$ ) but no difference in cardiac or neurological events [53]. Combined perioperative stroke and death was higher in diabetics $(2 \%$ vs. $0.9 \%, \mathrm{P}=0.006$ ) and the significance was sustained in multivariate analysis. Follow up showed no differences between the two groups in the estimated 7-year ipsilateral and overall stroke and mortality rates. Insulin dependence showed no early or late associated risks. Similar results were reported in another series reviewing 2,196 carotid interventions (1,196 CEA, 1,080 CAS); diabetes was associated with a threefold risk of 30-day post-CEA stroke and death (OR 2.8, 95\% CI 1.05-7.60; $\mathrm{P}=0.04$ ) [54]. However, In the CAS group, neither diabetes nor insulin could predict outcomes. Excluding the perioperative period, 
the 6-year stroke and death rates were similar for either procedure irrespective of diabetic status. The authors suggested that CAS may be preferred in selected diabetic patients, given the higher perioperative risks of CEA; however further evidence is needed to support this.

Overall, diabetic patients undergoing CEA should be anticipated to experience slightly higher perioperative events, partly related to preexisting silent myocardial ischemia. This perioperative risk though remains largely below the limits recommended by published guidelines, confirming the feasibility and safety of CEA in diabetic patients. A thorough preoperative cardiac evaluation and risk factor control could ameliorate these events, but diabetic patients with multiple other comorbidities should be also considered for CAS.

\section{Restenosis after carotid revascularization}

Carotid restenosis is an important parameter of the long term outcomes after CEA or CAS that could limit their long-term efficacy as it can lead to recurrent ischemic events. Carotid restenosis is generally attributed to neointimal hyperplasia when occurring within the first 2 years, or to recurrence of underlying atherosclerotic disease thereafter $[55,56]$. The secondary analysis of the most recent and largest randomized controlled trial "Carotid Revascularization Endarterectomy vs. Stenting Trial" (CREST) comparing outcomes of CAS vs. CEA in 2502 patients reported a $>70 \%$ restenosis rate of $6 \%$ after CAS, which was comparable with the $6.3 \%$ restenosis rate after CEA at 2 years [57]. It was demonstrated that after adjusting for age, sex and symptomatic status, diabetes was a predictor of restenosis at 2 years for both CEA (HR 2.35, 95\% CI 1.43-3.86) and CAS (HR 2.44, 95\% CI 1.46- 4.08). Previous large single-institution studies of CEA and CAS and studies of coronary arteries have implied that diabetes and poor preprocedural glycemic control are risk factors for recurrent stenosis $[54,56-60]$. It is speculated that the presence of diabetes can both increase neointimal hyperplasia after arterial injury and accelerate the growth of new carotid plaques at the site of CEA. The presence of periprocedural hyperglycemia may otherwise induce an inflammatory and oxidative stress burden on the vessel wall that accelerates the early phase cascade the restenosis [60].

\section{Conclusion}

Carotid atherosclerosis is a significant contributor of diabetic patients' morbidity and mortality. Surveillance for carotid artery disease, even at its early stages, can point patients at high risk for cardiovascular events and guide the intensity of primary and secondary prevention strategies, as well as the optimal management, medical, surgical or endovascular. Higher rates of postoperative adverse events and higher rates of long term carotid restenosis should be anticipated in diabetic patients after carotid revascularization.

\section{References}

1. Adams HP Jr, Bendixen BH, Kappallie LJ, Biller J, Love BB, et al. (1993) Classification of subtype of acute ischemic stroke. Definitions for use in a multicenter clinical trial, TOAST. Trial of Org 10172 in acute stroke treatment. Stroke 24: 35-41.

2. Himmelmann A, Hansson L, Svensson A, Harmsen P, Holmgren C, et al (1998) Predictors of stroke in elderly. Acta Med Scand 224: 439-443.

3. Stamler J, Vaccaro O, Neaton JD, Wendworth D (1993) Diabetes, other risk factors, and 12-yr cardiovascularmortality for menscreened in the multiple risk factor intervention trial. Diabetes care 16: 434-444.

4. Kameyama M, Fushimi H, Udaka F (1994) Diabetes mellitus and cerebra vascular disease. Diabetes Res Clin Practice 24: S205-208.

5. Bonora E, Kiechl S, Oberhollenzer F, Egger G, Bonadonna RC, et al. (2000) Impaired glucose tolerance, Type II diabetes mellitus and carotid atherosclerosis: prospective results from the Bruneck Study. Diabetologia 43 156-164.

6. Inukai $\mathrm{T}$, Yamamoto $\mathrm{R}$, Suetsugu $\mathrm{M}$, Matsumoto $\mathrm{S}$, Wakabayashi $\mathrm{S}$, et al (2005) Small low-density lipoprotein and small low-density lipoprotein/total lowdensity lipoprotein are closely associated with intima-media thickness of the carotid artery in Type 2 diabetic patients. J Diabetes Complications 19 269-275.

7. Choi SW, Shin MH, Yun WJ, Kim HY, Lee YH, et al. (2011) Association between hemoglobin A1c, carotid atherosclerosis, arterial stiffness, and periphera arterial disease in Korean type 2 diabetic patients. J Diabetes Complications 25: 7-13.

8. Giannarelli C, Bianchini E, Bruno RM, Magagna A, Landini L, et al. (2012) Local carotid stiffness and intima-media thickness assessment by a novel ultrasoundbased system in essential hypertension. Atherosclerosis 223: 372-377.

9. Matsumoto K, Sera Y, Nakamura H, Ueki Y, Miyake S (2002) Correlation between common carotid arterial wall thickness and ischemic stroke in patients with type 2 diabetes mellitus. Metabolism 51: 244-247.

10. Li LX, Wu X, Lu JX, Tu YF, Yu LB, et al. (2014) Comparison of carotid and lower limb atherosclerosis in both previously known and newly diagnosed type 2 diabetes mellitus. J Diabetes Investig 5: 734-742.

11. Lundman P, Keech AC, Griffiths K, Pillai A, Celermajer DS (2005) New carotid plaque formation is very common in adult patients with Type 2 diabetes mellitus. Diabet Med 22: 355-356.

12. Lacroix P, Aboyans V, Criqui MH, Bertin F, Bouhamed T, et al. (2006) Type-2 diabetes and carotid stenosis: a proposal for a screening strategy in asymptomatic patients. Vasc Med 11: 93-99.

13. Yuan C, Lai CW, Chan LW, Chow M, Law HKW, et al. (2014) Cumulative effects of hypertension, dyslipidemia and chronic kidney disease on carotid atherosclerosis in Chinese patients with type 2 diabetes mellitus. J Diabetes Res.

14. Luo X, Yang Y, Cao T, Li Z (2011) Differences in the left and right carotid intima- media thickness and associated risk factors. Clin Radiol 66: 393-398.

15. Jia Q, Zheng H, Zhao X, Wang C, Liu G, et al. (2012) Abnormal glucose regulation in patients with Acute stroke cross china, Prevalence and baseline patient characteristics. Stroke 43: 650-657.

16. Sun Y, Paul M, Toh HS (2009) Impact of Diabetes Mellitus (DM) on the HealthCare Utilization and Clinical Outcomes of Patients with Stroke in Singapore. Int Soc Pharm Outcomes Res (ISPOR) 1098-3015, S101-S105.

17. Kernan WN, Viscoli CM, Inzucchi SE, Brass LM, Bravata DM, et al. (2005) Prevalence of abnormal glucose tolerance following a transient ischemic attack or ischemic stroke. Arch Intern Med 165: 227-233.

18. Megherbi SE, Milan C, Minier D, Couvreur G, Osseby GV, et al. (2003) Association between diabetes and stroke subtype on survival and functional outcome 3 months after stroke data from the European BIOMED Stroke Project. Stroke 34: 688-694.

19. Kaarisalo MM, Raiha I, Sivenius J, Immonen Raiha P, Lehtonen A, et al. (2005) Diabetes worsens the outcome of acute ischemic stroke. Diabetes Res Clin Pract 69: 293-298.

20. Weimar C, Ziegler A, Konig IR, Diener HC (2002) Predicting functional outcome and survival after acute ischemic stroke. J Neurol 249: 888-895.

21. Jia Q, Zhao X, Wang C, Wang Y, Yan Y, et al. (2011) Diabetes and poo outcomes within 6 months after acute ischemic stroke: the China National Stroke Registry. Stroke 42: 2758-2762.

22. Toyoda K, Okada Y, Kobayashi S (2007) Early recurrence of ischemic stroke in Japanese patients: The Japan standard stroke registry study. Cerebrovasc Dis 24: 289-295

23. Fu JH, Lv CZ, Hong Z (2003) The observation of the recurrence and Prognosis of Ischemic Stroke in Diabetic Patients. Chin J Diabetes 11: 386-390.

24. Peppa-Patrikiou M, Scordill A, Antoniou A, Giannaki M, Dracopoulou M, et al (1998) Carotid atherosclerosis in adolescents and young adults with IDDM, relation to urinary endothelin, albumin, free cortisol and other factors. Diabetes Care 21: 1004-1007.

25. Giurgea GA, Nagi K, Gschwandtner M, Hobaus C, Hortenhuber T, et al. (2015) Gender metabolic control and carotid intima-media thickness in children and adolescent with type 1 diabetes mellitus. Wien Klin Wochenschr 127: 116-123. 
Citation: Siddiqui NA, Moosa A, Shaikh F, Saleh W, Efthymios A (2019) Carotid Artery Disease in Diabetic Patients: Contemporary Perspectives. J Blood Lymph 9: 238.

26. Khoury JC, Kleindorfer D, Alwell K, Moomaw CJ, Woo D, et al. (2013) Diabetes mellitus: a risk factor for ischemic stroke in a large biracial population. Stroke 44: 1500-1504

27. Rohr J, Kittner S, Feeser B, Hebel JR, Whyte MG, et al. (1996) Traditional risk factors and ischemic stroke in yound adults. Arch Neurol 53: 603-607.

28. Avgerinos ED, Kadoglou NP, Moulakakis KG, Giannakopoulos TG, Liapis CD (2011) Current role of biomarkers in carotid disease: a systematic review. Int J Stroke 6: 337-345.

29. Kadoglou N, Avgerinos ED, Liapis CD (2010) An update on markers of carotid atherosclerosis in patients with Type 2 diabetes. Biomarkers Med 4: 601-609.

30. Burke AP, Kolodgie FD, Zieske A, Fowler DR, Weber DK, et al. (2004) Morphologic findings of coronary atherosclerotic plaques in diabetics: a postmortem study. Arterioscler Thromb Vasc Biol 24: 1266-1271.

31. Moreno PR, Murcia AM, Palacios IF, Leon MN, Bernardi VH, et al. (2000) Coronary composition and macrophage infiltration in atherectomy specimens from patients with diabetes mellitus. Circulation 102: 2180-2184.

32. Olson FJ, Stromberg S, Hjelmgren O, Kjelldahl J, Fagerberg B, et al. (2011) Increased vascularization of shoulder regions of carotid atherosclerotic plaques from patients with diabetes. J Vasc Surg 54: 1324-1331.

33. Edsfeldt A, Goncalves I, Grufman H, Nitulescu M, Duner P, et al. (2014) Impaired fibrous repair: a possible contributor to atherosclerotic plaque vulnerability in patients with type II diabetes. Arterioscler Thromb Vasc Biol 34: $2143-2150$

34. Esposito L, Saam T, Heider P, Bockelbrink A, Pelisek J, et al. (2010) MRI plaque imaging reveals high-risk carotid plaques especially in diabetic patients irrespective of the degree of stenosis. BMC Med Imaging 10: 1-27.

35. Wackers FJ, Young LH, Inzucchi SE, Chyun DA, Davey JA, et al. (2004) Detection of Ischemia in Asymptomatic Diabetics Investigators the DIAD study. Diabetes Care 27: 1954-1961.

36. Katakami N, Kaneto H, Shimomura I (2014) Carotid ultrasonography: A potent tool for better clinical practice in diagnosis of atherosclerosis in diabetic patients. J Diabetes Invest 5: 3-13.

37. Lorenz MW, Markus HS, Bots ML, Rosvall M, Sitzer M (2007) Prediction of clinical cardiovascular events with carotid intima-media thickness: a systematic review and meta-analysis. Circulation 115: 459-467.

38. Yamasaki Y, Kodama M, Nishizawa H, Sakamoto K, Matsuhisa M, et al. (2000) Carotid intima-media thickness in Japanese type 2 diabetic subjects: predictors of progression and relationship with incident coronary heart disease. Diabetes Care 23: 1310-1315.

39. Inaba Y, Chen JA, Bergmann SR (2012) Carotid plaque, compared with carotid intima-media thickness, more accurately predicts coronary artery disease events: A meta-analysis. Atherosclerosis 220: 128-133.

40. Gerstein HC, Miller ME, Byington RP (2008) Effects of intensive glucose lowering in type 2 diabetes. N Engl J Med 358: 2545-2559.

41. Patel A, MacMahon S, Chalmers J (2008) Intensive blood glucose control and vascular outcomes in patients with type 2 diabetes. N Engl J Med 358: 25602572

42. Brott TG, Halperin JL, Abbara S, Bacharach JM, Barr JD et al. (2011) ASA ACCF/AHA/AANN/AANS/ACR/ ASNR/CNS/SAIP/SCAI/SIR/SNIS/SVM/SVS guideline on the management of patients with extracranial carotid and vertebral artery disease: executive summary. J Am Coll Cardiol 57: 1002-1044.

43. Luscher TF, Creager MA, Beckman JA, Cosentino F (2013) Diabetes and vascular disease: Pathophysiology, clinical consequences and medical therapy: part II. Eur Heart J 34: 2444-2452.
44. Holman RR, Paul SK, Bethel MA, Matthews DR, Neil HA (2008) 10-year followup of intensive glucose control in type 2 diabetes. N Engl J Med 359: 15771589

45. UK-TIA Study Group (1988) United Kingdom transient ischaemic attack (UK TIA) aspirin trial: interim results. Br Med J (Clin Res Ed) 296: 316-320.

46. ACCORD Study Group Cushman WC, Evans GW, Byington RP (2010) Effect of intensive blood-pressure control in type 2 diabetes mellitus. $\mathrm{N}$ Engl $\mathrm{J}$ Med 362: $1575-1585$

47. American Diabetes Association (2015) Cardiovascular disease and risk management. Diabetes Cre suppl: S49-S57

48. Liapis CD, Bell PR, Mikhailidis D, Sivenius J, Nicolaides A, et al. (2010) ESVS guidelines. Section A- Prevention in patients with carotid artery stenosis. Cur Vasc Pharmacol 8: 673-681.

49. Liapis CD, Bell PR, Mikhailidis D, Sivenius J, Nicolaides A, et al. (2009) ESVS Guidelines Collaborators. ESVS guidelines, Invasive treatment for carotid stenosis: indications-techniques. Eur J Vasc Endovasc Surg 37: S1-S19.

50. Tripolt NJ, Narath SH, Eder M, Pieber TR, Wascher TC, et al. (2014) Multiple risk factor intervention reduces carotid atherosclerosis in patients with type 2 diabetes. Cardiovasc Diabetol 13: 95

51. Goldstein LB, Bushnell CD, Adams RJ, Appel LJ, Braun LT, et al. (2011) Guidelines for the Primary Prevention of Stroke: A Guideline for Healthcare Professionals from the American Heart Association/American Stroke Association. Stroke 42: 517-584.

52. Stoner MC, Abbott WM, Wong DR, Hua HT, Lamuraglia GM, et al. (2006) Defining the high-risk patient for carotid endarterectomy: an analysis of the prospective National Surgical Quality Improvement Program database. J Vasc Surg 43: 285-296.

53. Dorigo W, Pulli R, Pratesi G, Fargion A, Marek J, et al. (2011) Early and long term results of carotid endarterectomy in diabetic patients. J Vasc Surg 53: 44-52.

54. Parlani G, de Rango P, Cieri E, Verzini F, Giordano G, et al. (2012) Diabetes is not a predictor of outcome for carotid revascularization with stenting as it may be for carotid endarterectomy. J Vasc Surg 55: 79-89.

55. Avgerinos ED, Kakisis JD, Moulakakis MS, Giannakopoulos TG, Sfyroeras G et al. (2013) Statins influence long term restenosis and cardiovascular events following carotid endarterectomy. Curr Vasc Pharmacol 13: 239-247.

56. Lal BK, Beach KW, Roubin GS, Lutsep HL, Moore WS, et al. (2012) Restenosis after carotid artery stenting and endarterectomy: a secondary analysis of CREST, a randomized controlled trial. Lancet Neurol 11: 755-763.

57. Abizaid A, Kornowski R, Mintz GS, Hong MK, Abizaid AS, et al. (1998) The influence of diabetes mellitus on acute and late clinical outcomes following coronary stent implantation. J Am Coll Cardiol 32: 584-589.

58. Reina-Gutierrez T, Serrano-Hernando FJ, Sancjez-Hervas L, Ponce A, de Ceniga MV, et al. (2005) Recurrent carotid stenosis following endarterectomy natural history and risk factors. Eur J Vasc Endovasc Surg 29: 334-34.

59. Fluri F, Hatz F, Voss B, Lyrer PA, Engelter ST (2010) Restenosis after carotid endarterectomy: significance of newly acquired risk factors. Eur J Neurol 17 493-498.

60. Marfella R, Sasso FC, Siniscalchi M, Paolisso P, Rizzo MR, et al. (2012) Peri-procedural tight glycemic control during early percutaneous coronary intervention is associated with a lower rate of in-stent restenosis in patients with acute ST-elevation myocardial infarction. J Clin Endocrinol Metab 97: 2862-2871. 